\title{
One-Year Adherence to Warfarin Treatment for Venous Thromboembolism in High-Risk Patients and Its Association with Long-term Risk of Recurrent Events
}

\author{
Shih-Yin Chen, PhD; Ning Wu, PhD; Michael Gulseth, PharmD, BCPS; \\ Joyce LaMori, MHS, MBA; Brahim K. Bookhart, MBA, MPH; \\ Luke Boulanger, MA, MBA; Larry Fields, MD; and Jeff Schein, DrPH, MPH
}

\begin{abstract}
BACKGROUND: Warfarin is the predominant oral anticoagulant used for the prevention of recurrent venous thromboembolism (VTE) events. However, its long-term use is complicated by the need to manage the drug within a narrow therapeutic range and by possible food and drug interactions.
\end{abstract}

OBJECTIVE: To examine the association between 1-year adherence, measured through compliance with and persistence on warfarin treatment for VTE, and long-term risk of recurrent events among patients at high risk.

METHODS: Medical and pharmacy claims for patients with commercial or Medicare supplemental insurance in the Thomson Reuters MarketScan database were analyzed. Adult patients with medical claims with an associated VTE diagnosis between January 1, 2006, and March 31, 2008, were identified. The index date was defined as the date of the first observed VTE claim or the date of discharge if the index event was a hospital stay. Highrisk patients (patients with cancer, or noncancer patients who did not have reversible risk factors during the 3-month period prior to the index date) who filled a warfarin prescription within 2 weeks of the index date were included. Persistence was evaluated in terms of discontinuation, defined as a 90-day gap in warfarin supply during a 1-year assessment period following the index date. Compliance was measured by the proportion of days covered (PDC) over the 1-year assessment period, with PDC $<0.8$ defined as noncompliance. Recurrent VTE events were identified as hospitalizations where VTE was the primary diagnosis after the 1-year assessment period and until patients were lost to follow-up. The association between adherence to warfarin therapy and VTE recurrence was evaluated descriptively via Kaplan-Meier curves and a Cox proportional hazards model, adjusted for patient demographic and clinical characteristics. A similar analysis using the medication possession ratio (MPR) as a measure of compliance was also performed in a subset of patients who had filled at least 2 warfarin prescriptions.

RESULTS: The study included 8,040 VTE patients identified as being at high risk of recurrence (mean age 61 years, $59.4 \%$ male), of whom $76.9 \%$ were not compliant with warfarin therapy based on PDC, and $51.5 \%$ discontinued therapy. Among those with at least 2 warfarin prescriptions $(n=7612)$, $34.1 \%$ of high-risk patients were not compliant with warfarin therapy between the first and last refills based on MPR. Kaplan-Meier curves showed that patients who were compliant or continued warfarin therapy were less likely to experience a VTE event (all $P<0.05$ ). Noncompliant patients had a 3 times greater risk of VTE recurrence than compliant patients, based on PDC (hazard ratio $[\mathrm{HR}]=3.01,95 \%$ confidence interval [Cl]: 1.28-4.97). Among the subpopulation who filled at least 2 warfarin prescriptions, noncompliant patients (based on MPR) were also found to be more likely to have recurrent VTE events, compared with compliant patients ( $\mathrm{HR}=1.60,95 \% \mathrm{Cl}: 1.18-2.16)$. Patients who discontinued warfarin were more likely to have recurrent VTE events compared with patients who did not discontinue on warfarin treatment $(\mathrm{HR}=1.48,95 \% \mathrm{Cl}: 1.09-2.01)$.
CONCLUSION: Adherence to a year of therapy was low in patients at high risk of recurrent VTE, even though long-term therapy should be considered in this population. Noncompliance and discontinuation of warfarin treatment over a 1-year period was associated with a higher risk of recurrent VTE. Future research should investigate and differentiate between patient and provider discontinuation to develop strategies to improve compliance and persistence with appropriate anticoagulation therapy that may potentially reduce recurrent VTE.

J Manag Care Pharm. 2013;19(4):291-301

Copyright $\odot 2013$, Academy of Managed Care Pharmacy. All rights reserved.

\section{What is already known about this subject}

- Guidelines recommend long-term oral anticoagulation therapy for patients with venous thromboembolism (VTE) who are at high risk of recurrent events.

- Past studies investigating real-world treatment patterns found that many patients only receive a short duration of treatment with warfarin, but data regarding the impact of short-term therapy on long-term risk of recurrent events in high risk patients are limited.

\section{What this study adds}

- This study assessed the adherence of patients at high risk of recurrent VTE events to year-long oral anticoagulant therapy and found that compliance and persistence to therapy was suboptimal.

- Our findings suggest that poor compliance and persistence to long-term anticoagulant therapy were associated with an increased risk of recurrence in high-risk patients.

- Such associations should be considered, along with risk-to-benefit ratio and patient preference, when managing high-risk patients.

$\mathrm{V}$ enous thromboembolism (VTE), a blood clot that forms in the vein, can be classified as deep vein thrombosis (DVT) or pulmonary embolism (PE). Each year, VTE affects 300,000 to 600,000 individuals in the United States. ${ }^{1}$ The incidence of VTE is about 100 events per 100,000 individuals in the United States and increases with age. ${ }^{2}$ Of all VTE events, approximately two thirds manifest as DVT and one third manifests as PE. ${ }^{2}$ VTE can lead to serious consequences. 
Of patients who were hospitalized due to DVT, the mortality rate within 3 months following hospital discharge was 13.0\% among patients with PE and 5.4\% among patients with DVT. ${ }^{3}$ VTE often recurs a few months after the initial VTE event. The recurrence rate is estimated to be $7 \%-8 \%$ up to 6 months after the initial event ${ }^{2}$ and is known to persist over time. ${ }^{4-6}$

The American College of Physicians and the American Academy of Family Physicians guidelines for VTE treatment suggest 3 to 6 months of anticoagulation therapy following a first VTE and 12 months (or longer) of therapy after 2 or more VTE events. ${ }^{7}$ The 8th edition of the American College of Chest Physicians (ACCP) Consensus Guidelines recommends an individualized duration of anticoagulant therapy according to risk of VTE recurrence and other complications (e.g., bleeding). ${ }^{8}$ For patients with VTE secondary to a reversible risk factor or with a first unprovoked VTE, the guidelines recommend treatment with anticoagulant for at least 3 months. For patients with unprovoked VTE and a low risk of bleeding, a second episode of unprovoked DVT, or cancer (i.e., patients with a high risk of recurrent VTE), the guidelines recommend indefinite anticoagulant therapy. ${ }^{8}$ Anticoagulant therapy should be continued until its risks (i.e., increase in bleeding) outweigh the benefits of reducing recurrent VTE events.

In clinical practice, warfarin remains the most commonly used oral anticoagulant, but its use is complicated by the requirement for frequent monitoring and its interactions with food and other drugs. ${ }^{9}$ Due to warfarin's long half-life and various factors influencing its pharmacodynamics, patients receiving warfarin must be monitored carefully through the assessments of international normalized ratios (INRs), a blood test that detects over- or under-coagulation. ${ }^{8,9}$

Several past studies have examined warfarin utilization in a real-world setting through large administrative claims databases and have reported that its use is suboptimal. ${ }^{10-12}$ A study by Ganz et al. investigated whether oral anticoagulation was given for at least 3 months after DVT or PE, and it assessed which factors predicted reduced duration of therapy. ${ }^{10}$ The authors reported that $25 \%$ of patients had a duration of oral anticoagulant therapy of less than 90 days. ${ }^{10}$ A similar study conducted by Deitelzweig and colleagues found that $63 \%$ of their patients discontinued warfarin therapy within a 1-year period, with $12 \%$ discontinuing within 3 months. ${ }^{11}$ Another study by Willey et al. found the average duration of therapy to be 6.6 months. ${ }^{12}$

Although real-world data for anticoagulant utilization among patients with VTE have been published, the impact of compliance and persistence to long-term anticoagulant therapy among high-risk patients has not been fully investigated. In high-risk patients for whom long-term therapy is recommended, compliance and persistence may play an important role in treatment effectiveness and may be associated with recurrence of VTE events. The objective of this study is to help fill this gap in the literature by examining associations between long-term compliance with and persistence on warfarin therapy and risk of VTE recurrence among high-risk patients.

\section{Methods}

\section{Data Source}

A retrospective cohort study was conducted using administrative claims dated from January 1, 2005, to March 30, 2009, in the Thomson Medstat's MarketScan Commercial and Medicare Supplemental Insurance Databases (Thomson Reuters Healthcare Inc., Ann Arbor, Michigan). These databases provide comprehensive information on insurance status and health care services received by individuals who are enrolled in geographically distributed health plans in the United States. All records are linked through encrypted, unique, patient-level identifiers that allow for longitudinal tracking of each individual's health care utilization. Demographic and health insurance plan characteristics such as age, gender, U.S. geographic region of residence, health plan type, and enrollment status are available in the files. Detailed health care encounters of both inpatient and outpatient care are recorded in the medical services claims, which include date and place of service(s), provider type, payments, and up to 15 International Classification of Diseases, Ninth Revision, Clinical Modification (ICD-9-CM) diagnosis and procedure codes. Pharmacy claims contain information on filled prescriptions, including National Drug Code, prescription fill dates, quantity dispensed, days supply, and plan- and patient-paid costs.

As all data were encrypted and Health Insurance Portability and Accountability Act (HIPAA)-compliant, this study was exempt from Institutional Review Board review.

\section{Study Sample Selection}

Commercially insured (aged 18-64 years) and Medicare supplemental-insured (aged $\geq 65$ years) individuals who had medical claims with associated diagnoses suggesting VTE and who initiated warfarin within 2 weeks of a first VTE event between January 1, 2006, and March 31, 2008, were selected. Two weeks were allowed for prescriptions to appear in pharmacy claims, in the event that a patient was discharged with several doses of anticoagulants. Patients with VTE were identified as those who had medical claims associated with the following ICD-9-CM diagnosis codes for DVT: 451.1x, 451.2x, 453.0x, $453.2,453.3 \mathrm{x}, 453.40,453.41,453.42,453.8 \mathrm{x}, 997.2 \mathrm{x}$ or with the ICD-9-CM code for PE: 415.1x. The date of the first observed claim with a VTE diagnosis was set as the index date. We further selected patients who were at high risk as defined by the ACCP guidelines, i.e., patients with cancer or noncancer patients who did not have reversible risk factors for VTE during the 3-month period prior to the index date. Risk factors used to define high-risk patients are listed in the Appendix.

Patients who met the following criteria were selected for 


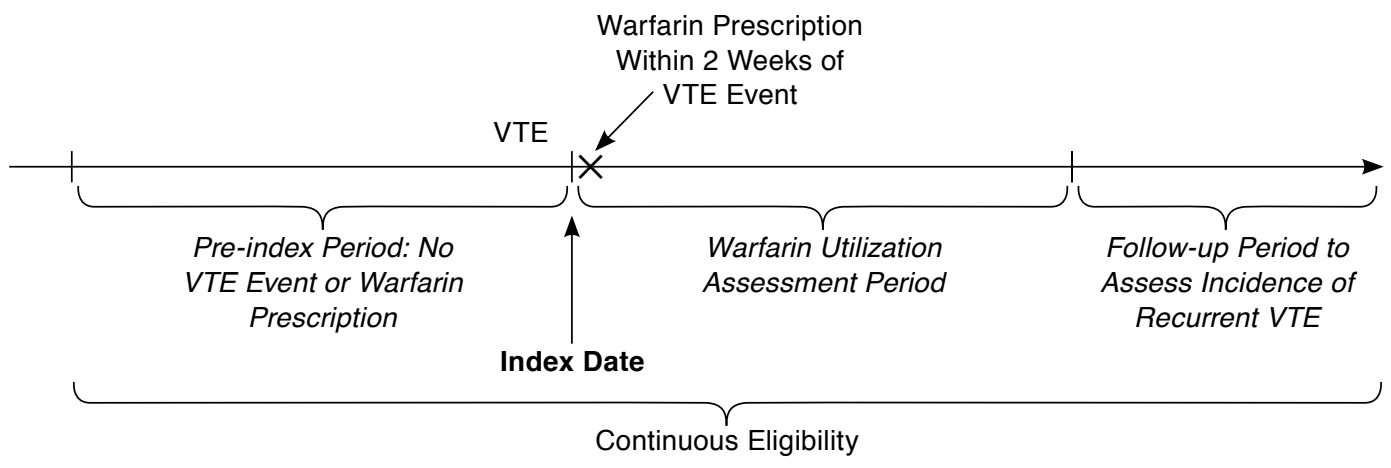

VTE $=$ venous thromboembolism

further analysis: (1) were continuously enrolled in a health plan during the 12 months prior to the index date and for 12 months after the date of the first fill of warfarin; (2) had no claims for warfarin, VTE, or atrial fibrillation (AF) during the 12-month pre-index period; and (3) had no claims for contraindications to warfarin use, including major bleeding, cirrhosis, hepatitis, seizure disorder, mechanical fall, and dementia in the 12 months prior to the index date. Subjects with a VTE event during the 12-month period after the first warfarin prescription fill (referred to as the warfarin utilization assessment period) were also excluded from this analysis. These patients were excluded to avoid assessing exposure and outcome during the same period; any recurrent VTE during the warfarin utilization assessment period might influence patient compliance with treatment and, therefore, subsequent clinical outcomes. Including such patients in the analysis might have created a bias in associations between warfarin utilization and subsequent recurrence of VTE. To understand whether our findings were robust, we also conducted a sensitivity analysis by relaxing this exclusion criterion.

\section{Study Cohorts}

Study cohorts were created based on patients' compliance and persistence with warfarin therapy. Compliance was assessed based on the pharmacy claims in the 12 months after the first warfarin prescription fill (Figure 1). Although ACCP guidelines recommend indefinite anticoagulant therapy that is individualized according to risk and benefit, ${ }^{8}$ we chose 1 year as the unit of our evaluation. Compliance with warfarin treatment was measured using both proportion of days covered (PDC) and medication possession ratio (MPR). ${ }^{13}$ PDC was calculated as the total number of days covered with warfarin supply divided by 365 days. MPR was calculated as the number of days of supply dispensed during the 1-year warfarin utilization assessment period divided by the number of days between the first and last prescription refill. Numerators in the PDC and MPR calculation were truncated at 365 days so that the PDC and MPR were capped at $100 \%$. A subset of patients who had at least 2 warfarin prescriptions was assessed for MPR. Days of hospitalization were subtracted from both PDC and MPR measurements. These 2 measures were chosen because they use different assumptions when evaluating compliance. PDC assumes expected length of therapy to be a full year and considers discontinuation in its calculation. On the other hand, MPR measures only the compliance between the first and last observed refills. It does not consider the time once therapy was discontinued. Hence, MPR was only calculated if patients had at least 2 prescriptions (e.g., early discontinuers with just 1 prescription were excluded). Persistence was evaluated by treatment discontinuation, defined as a gap of at least 90 days in warfarin supply during the assessment period. Patients were considered discontinued whether or not they reinitiated the therapy at a later time, beyond the 90-day gap. Patients were classified into compliant and noncompliant cohorts based on the PDC and MPR measures. A cutoff point of 0.8 was defined to dichotomize patients as low $(<0.8)$ or high $(\geq 0.8)$ compliance. ${ }^{13}$ Patients were also classified into continued and discontinued warfarin treatment during the 12-month assessment period.

\section{Study Measures}

Patient demographics were assessed at the index date, including age, gender, geographic region (i.e., Northeast, Midwest, West, South), and health plan type. Comorbid conditions during the 12 months prior to the index date were measured using the Charlson Comorbidity Index (CCI) ${ }^{14}$ Recurrent VTE events were identified as hospitalizations where VTE was the primary diagnosis from 12 months after the index date (warfarin utilization assessment period) until patients were lost to follow-up (Figure 1). 


\section{Analysis}

Descriptive analyses were conducted for demographics, comorbidities, and VTE index event type by study cohort. Mean and standard deviation (SD) were reported for continuous variables (i.e., age). Student's t-tests were used to detect differences in continuous variables. Percentages were reported for categorical variables (i.e., region and health plan type), and chisquare tests were used to detect differences in these variables. Nonparametric Wilcoxon rank-sum tests were used to detect differences in count variables (i.e., CCI).

The association between warfarin utilization and recurrent VTE events was evaluated descriptively via Kaplan-Meier curves with log-rank tests. Cox proportional hazards models were estimated, adjusting for age, gender, region, whether the index event was PE, and CCI, to evaluate the association between warfarin utilization and recurrent VTE events. Hazard ratios (HRs) and 95\% confidence intervals (CIs) were reported. Separate models were estimated using PDC, MPR, and discontinuation, respectively.

\section{Sensitivity Analysis}

Patients who had a VTE event during the 12 months of the warfarin utilization assessment period were excluded from the primary analysis. These patients were included as part of a sensitivity regression analysis. Because early recurrent VTE events occurred in the warfarin utilization assessment period, associations between long-term therapy and risk of VTE events could not be evaluated for these patients. Early recurrent VTE events were therefore considered as confounders and entered into the regression models as a covariate, rather than as an outcome.

\section{Results}

\section{Demographics and Clinical Characteristics}

The study identified 8,040 patients with VTE who were at high risk of VTE recurrence. Of these, 7,612 patients were also included in the MPR analysis (Figure 2). The average age of the patients was 61.2 years (SD: 14.8) and the majority were male (59.4\%). During the year after the initiation of warfarin, $76.9 \%$ of patients had a PDC $<0.8$ and $51.5 \%$ discontinued therapy. Among those with at least 2 warfarin prescriptions, $34.1 \%$ had an MPR $<0.8$.

Compliant users, defined by $\mathrm{PDC} \geq 0.8$, were older than noncompliant users (63.3 years vs. 60.6 years, $P<0.001$, Table 1). Patients who used warfarin continuously were significantly older than those who discontinued (62.5 years vs. 60.0 years, $P<0.001)$. Sex distribution was significantly different between the compliant and noncompliant groups in analyses stratified by PDC and MPR measures, with compliant groups containing a higher proportion of males. Patients with a $P D C \geq 0.8$ and those who were continuous users were significantly more likely to be enrolled in comprehensive plans and less likely to be enrolled in preferred provider organization plans, versus their respective comparators.

The majority of patients (84.6\%) had DVT as the initial VTE event. Patients with a PDC $\geq 0.8$ were more likely to have DVT as the initial VTE event than those with a PDC $<0.8(86.9 \%$ vs. $83.9 \%, P=0.006$ ), as were patients who used warfarin continuously compared with patients who discontinued warfarin ( $86.5 \%$ vs. $82.9 \%, P<0.001)$. The distribution of CCI scores was significantly different between MPR cohorts and between continued and discontinued cohorts. A significantly lower proportion of patients with $\mathrm{CCI} \geq 4$ were seen in the MPR $\geq 0.8$ cohort than in the MPR $<0.8$ cohort ( $13.4 \%$ vs. $16.2 \%$, $P=0.011$ ). Among continued warfarin users, there was a higher proportion of patients with $\mathrm{CCI} \geq 4(15.5 \%$ vs. $13.6 \%)$ and a lower proportion of patients with $\mathrm{CCI}=0(48.1 \%$ vs. $52.8 \%)$ compared with patients who discontinued warfarin $(P<0.001)$.

\section{VTE Recurrence}

Overall, 2.2\% of patients experienced a recurrent VTE following the 1-year warfarin assessment period. On average, patients with a PDC $<0.8$ had a recurrent VTE sooner than patients with a $P D C \geq 0.8$ during the follow-up period $(P<0.001$, Figure 3$)$. Similarly, patients with an MPR $<0.8$ generally experienced a VTE event sooner than those with an $\mathrm{MPR} \geq 0.8 \quad(P=0.003)$. Discontinuation was also associated with a higher risk of recurrent VTE events: patients who discontinued use of warfarin generally experienced a VTE event sooner than those who continued warfarin $(P=0.024)$. Average length of follow-up, rate of recurrent VTE events during follow-up, and average number of days to recurrent VTE events for the study cohorts are presented in Table 2 .

Using Cox proportional hazards regressions to adjust for patient demographic and clinical characteristics, we found noncompliant users, defined as those having a $\operatorname{PDC}<0.8$, had a 3 times greater risk of recurrent VTE events than compliant patients with a $\mathrm{PDC} \geq 0.8(\mathrm{HR}=3.01,95 \% \mathrm{CI}: 1.28-4.97$, Table 3$)$. Among the subpopulation who filled at least 2 warfarin prescriptions, noncompliant users with an MPR $<0.8$ were also found to have a $60 \%$ increased risk of recurrent VTE events compared with compliant users with an $\mathrm{MPR} \geq 0.8$ ( $\mathrm{HR}=1.60$, 95\% CI: 1.18-2.16). Patients who discontinued warfarin therapy had a $48 \%$ higher risk of recurrent VTE events compared with patients who continued on warfarin ( $\mathrm{HR}=1.48$, 95\% CI: 1.09-2.01). Other demographic and clinical characteristics included in the model were not significantly associated with recurrent VTE events.

\section{Sensitivity Analysis}

In the sensitivity analysis, following the inclusion of patients who had VTE events during the warfarin utilization assessment period, the sample size increased from to 8,040 to 8,237 for the PDC/discontinuation analysis and from 7,612 to 7,802 
One-Year Adherence to Warfarin Treatment for Venous Thromboembolism in High-Risk Patients and Its Association with Long-term Risk of Recurrent Events

\section{FIGURE 2 Sample Selection}

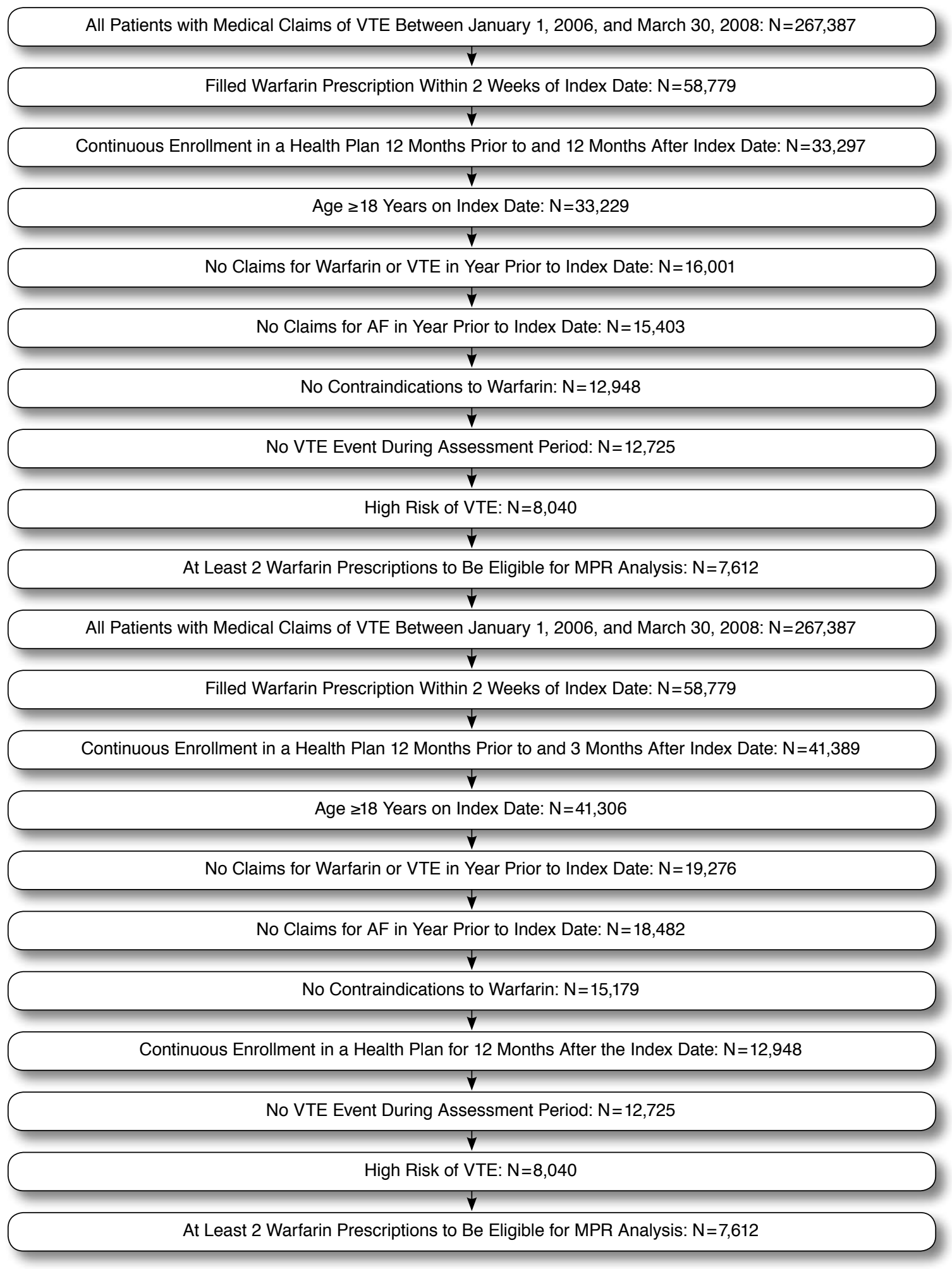

$A F=$ atrial fibrillation; $M P R=$ medication possession ratio; VTE= venous thromboembolism 


\section{TABLE 1 Demographic and Clinical Characteristics}

\begin{tabular}{|c|c|c|c|c|c|c|c|c|c|}
\hline & \multicolumn{3}{|c|}{$\begin{array}{l}\text { PDC Analysis } \\
(\mathrm{N}=8,040)\end{array}$} & \multicolumn{3}{|c|}{$\begin{array}{l}\text { MPR Analysis } \\
(\mathrm{N}=7,612)\end{array}$} & \multicolumn{3}{|c|}{$\begin{array}{l}\text { Discontinuation Analysis } \\
(\mathrm{N}=8,040)\end{array}$} \\
\hline & $\begin{array}{c}\text { Non- } \\
\text { compliant }\end{array}$ & Compliant & $\begin{array}{c}P \\
\text { Value }^{\mathrm{a}}\end{array}$ & $\begin{array}{c}\text { Non- } \\
\text { compliant }\end{array}$ & Compliant & $\begin{array}{c}P \\
\text { Value }^{\mathrm{a}} \\
\end{array}$ & Discontinued & Continued & $\begin{array}{c}P \\
\text { Value }^{\mathrm{a}} \\
\end{array}$ \\
\hline Number of patients (\%) & $6,179(76.9)$ & $1,861(23.1)$ & & $2,593(34.1)$ & $5,019(65.9)$ & & $4,154(51.7)$ & $3,886(48.3)$ & \\
\hline Age: mean (SD) & $60.6(14.9)$ & $63.3(14.4)$ & $<0.001$ & $61.1(14.7)$ & $61.3(14.9)$ & 0.657 & $60.0(15.1)$ & $62.5(14.5)$ & $<0.001$ \\
\hline Age (\%) & & & $<0.001$ & & & 0.714 & & & $<0.001$ \\
\hline $18-44$ & 13.8 & 9.8 & & 13.2 & 12.7 & & 14.9 & 10.7 & \\
\hline $45-64$ & 49.0 & 45.5 & & 48.5 & 48.3 & & 49.4 & 46.9 & \\
\hline $65-74$ & 16.1 & 18.1 & & 16.8 & 16.4 & & 15.5 & 17.8 & \\
\hline $75+$ & 21.0 & 26.7 & & 21.6 & 22.7 & & 20.3 & 24.5 & \\
\hline Gender (\%) & & & 0.005 & & & 0.012 & & & 0.084 \\
\hline Male & 58.5 & 62.2 & & 57.9 & 60.9 & & 58.4 & 60.3 & \\
\hline Female & 41.5 & 37.8 & & 42.1 & 39.1 & & 41.6 & 39.7 & \\
\hline Region of residence & & & 0.157 & & & 0.033 & & & 0.009 \\
\hline Northeast & 9.1 & 8.7 & & 9.8 & 8.8 & & 8.7 & 9.3 & \\
\hline Midwest & 36.4 & 39.7 & & 35.4 & 38.4 & & 35.6 & 39.0 & \\
\hline South & 34.5 & 32.4 & & 35.2 & 33.0 & & 35.1 & 32.7 & \\
\hline West & 19.3 & 18.6 & & 19.1 & 18.9 & & 19.9 & 18.3 & \\
\hline Unknown & 0.7 & 0.6 & & 0.5 & 0.8 & & 0.7 & 0.7 & \\
\hline Health insurance plan type (\%) & & & $<0.001$ & & & 0.171 & & & $<0.001$ \\
\hline Comprehensive & 32.3 & 39.7 & & 32.1 & 35.0 & & 31.5 & 36.7 & \\
\hline Exclusive provider organization & 0.1 & 0.1 & & 0.2 & 0.1 & & 0.2 & 0.1 & \\
\hline Health maintenance organization & 12.6 & 11.1 & & 13.3 & 11.6 & & 13.3 & 11.1 & \\
\hline Point-of-service & 9.1 & 8.1 & & 8.8 & 9.1 & & 9.3 & 8.3 & \\
\hline Preferred provider organization & 42.8 & 38.6 & & 41.9 & 41.6 & & 42.4 & 41.2 & \\
\hline Point-of-service with capitation & 0.6 & 0.9 & & 0.7 & 0.7 & & 0.6 & 0.7 & \\
\hline Consumer-directed health plan & 0.8 & 0.6 & & 0.8 & 0.7 & & 1.0 & 0.6 & \\
\hline Missing & 1.7 & 1.0 & & 2.1 & 1.3 & & 1.9 & 1.2 & \\
\hline Index VTE event type (\%) & & & 0.006 & & & 0.856 & & & $<0.001$ \\
\hline DVT & 83.9 & 86.9 & & 84.7 & 84.8 & & 82.9 & 86.5 & \\
\hline $\mathrm{PE}$ & 8.2 & 6.9 & & 7.6 & 7.8 & & 8.9 & 6.8 & \\
\hline DVT and PE & 7.8 & 6.1 & & 7.7 & 7.4 & & 8.2 & 6.7 & \\
\hline Charlson Comorbidity Index score (\%) & & & 0.113 & & & 0.011 & & & $<0.001$ \\
\hline 0 & 51.1 & 48.6 & & 50.5 & 50.9 & & 52.8 & 48.1 & \\
\hline 1 & 9.4 & 10.9 & & 9.5 & 9.7 & & 9.6 & 10.0 & \\
\hline 2 & 19.0 & 20.6 & & 18.1 & 20.1 & & 18.8 & 20.0 & \\
\hline 3 & 5.9 & 5.8 & & 5.7 & 6.0 & & 5.3 & 6.5 & \\
\hline$\geq 4$ & 14.6 & 14.0 & & 16.2 & 13.4 & & 13.6 & 15.5 & \\
\hline
\end{tabular}

for the MPR analysis (Table 4). Noncompliance with and discontinuation of warfarin remained associated with a higher risk of recurrent VTE in the sensitivity analysis although the relative risk was smaller than observed in the main analysis. Measured by PDC, patients who were noncompliant had a 2.6 times greater risk of recurrent VTE events than compliant patients (HR $=2.58$, 95\% CI: 1.62-4.11) Among the subpopulation who filled at least 2 warfarin prescriptions, noncompliant users with an MPR $<0.8$ had a $58 \%$ increased risk of recurrent VTE events compared with compliant users with an MPR $\geq 0.8$
$(\mathrm{HR}=1.58,95 \% \mathrm{CI}: 1.17-2.12)$. Patients who discontinued warfarin therapy had a $43 \%$ higher risk of recurrent VTE events compared with patients who continued on warfarin ( $\mathrm{HR}=1.43$, 95\% CI: 1.06-1.92).

\section{Discussion}

Using administrative claims for commercially insured and Medicare supplemental-insured individuals, this study assessed associations between compliance with long-term warfarin treatment and recurrent VTE among patients who had a high risk of recurrent VTE. We hypothesized that, for these 


\section{FIGURE 3 Kaplan-Meier Curves of Recurrent VTE Events from the End of Warfarin Assessment Period (Day 365 from the Index Date)}
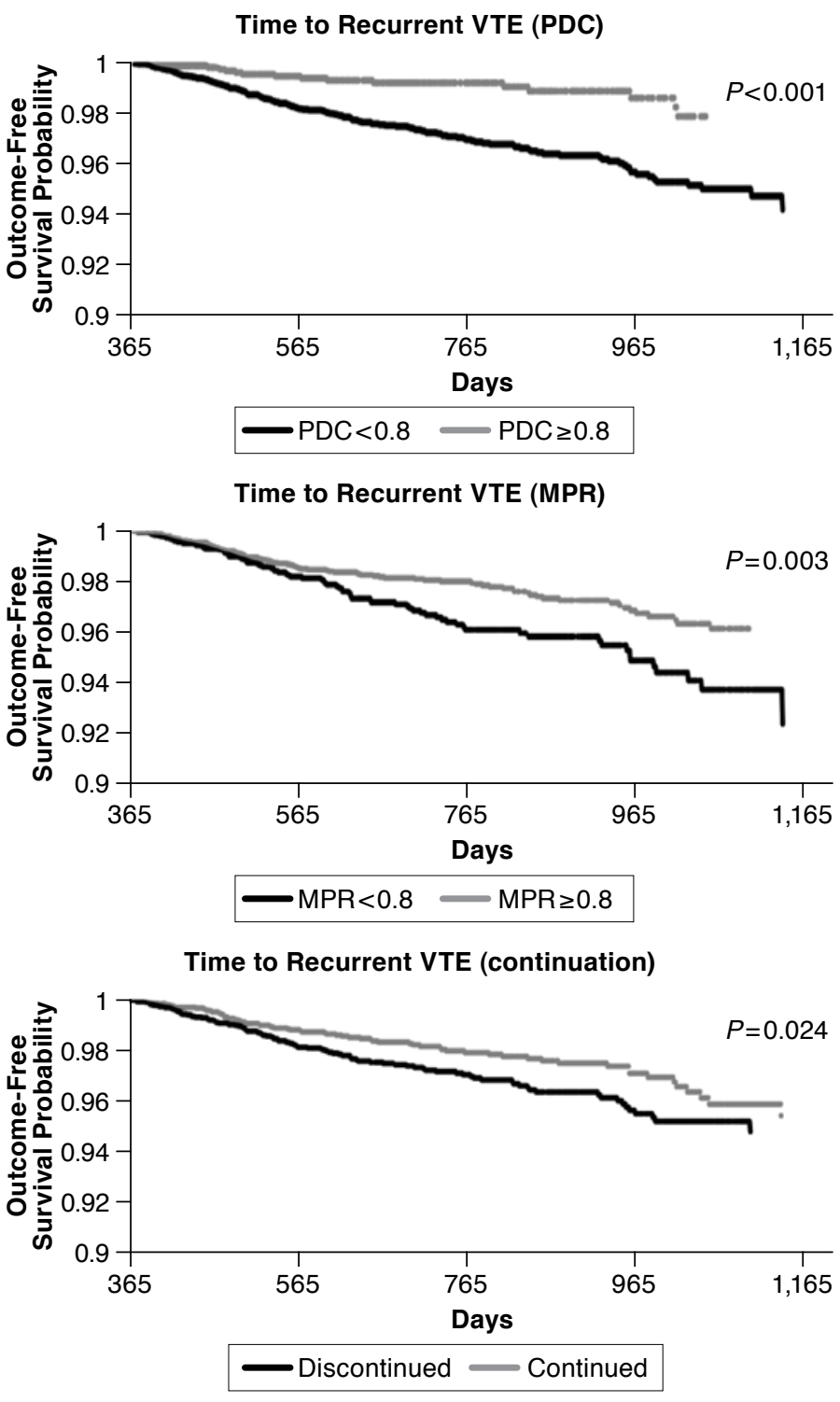

$\overline{M P R}=$ medication possession ratio; $P D C=$ proportion of days covered; $V T E=$ venous thromboembolism

patients, compliance and persistence would have a significant impact on risk of recurrence. Although the length of warfarin treatment for VTE should be individually tailored based on a patient's benefit-risk evaluation, our results suggest that regardless of how adherence to therapy was measured, patients who were not compliant with or who discontinued their warfarin therapy during 1 year had a higher risk of recurrent VTE events. The association observed in this study may help health care providers and managed care decision makers optimize care for these patients. Strategies to identify high-risk patients and interventions to assist these patients in complying with their therapies could be beneficial.

In the real world, the utilization of warfarin among all VTE patients is suboptimal, as reported in the scientific literature, ${ }^{10-12}$ but utilization has not been evaluated specifically in high-risk patients for whom long-term therapy is recommended. ${ }^{10-12}$ We found that more than half of high-risk patients discontinued warfarin therapy within 1 year of initiating treatment. When compliance was measured using PDC, $76.9 \%$ of subjects were not compliant with their warfarin treatment over 1 year. In our study, warfarin discontinuation was associated with an increased risk of recurrent VTE. These results are similar to a recent retrospective analysis that assessed the effects of warfarin discontinuation on rates of VTE recurrence among patients who had been hospitalized for an initial VTE event. ${ }^{11}$ Deitzelzwieg et al. reported that recurrent VTE was found in $10.9 \%$ of patients and also that discontinuation of treatment within 3 months, the time from index VTE to warfarin initiation, the duration of hospitalization, and previous VTE-related hospitalization were all predictors of VTE recurrence.

Because warfarin interacts with many medications and foods and has a long half-life, patients receiving warfarin are often at risk of over- or under-coagulation and need to be tested regularly to monitor their blood coagulation. INRs derived from prothrombin time are the strongest and most consistent predictors of bleeding complications. Out-of-range INRs are burdensome, carrying the potential for miscalculated dose adjustments, requiring careful monitoring of the patient, and often necessitating additional clinical visits and blood tests. ${ }^{15}$ Excessive fluctuations in INR, as well as any bleeding events that may result, are factors associated with discontinuation of warfarin therapy. ${ }^{16}$ Unfortunately, the administrative claims data used in this study do not allow us to determine whether INRs for these patients were well controlled. If patients were undergoing dosage adjustments to control INRs, they may have been misclassified as noncompliant if the prescribed medication lasted longer than initially intended, suggestive of a gap in therapy. However, such misclassifications would only result in an underestimate of the associations observed in this study.

Given the positive association between adherence to warfarin therapy and reduced VTE events, efforts should be made to improve adherence by both patients and physicians. Our study did not evaluate strategies for improving adherence, but a possible strategy, proposed in the literature, would be to improve physicians' awareness of and adherence to treatment guidelines. ${ }^{17}$ Alternatively, an improved understanding of the factors influencing compliance may help physicians to identify vulnerable subpopulations who should be targeted for further intervention or closer monitoring. ${ }^{16}$ Future research should investigate 


\begin{tabular}{|c|c|c|c|c|c|c|}
\hline & \multicolumn{2}{|c|}{$\begin{array}{l}\text { PDC Analysis } \\
(\mathrm{N}=8,040)\end{array}$} & \multicolumn{2}{|c|}{$\begin{array}{l}\text { MPR Analysis } \\
(\mathrm{N}=7,612)\end{array}$} & \multicolumn{2}{|c|}{$\begin{array}{l}\text { Discontinuation Analysis } \\
\qquad(\mathrm{N}=8,040)\end{array}$} \\
\hline & Noncompliant & Compliant & Noncompliant & Compliant & Discontinued & Continued \\
\hline Average length of follow-up (days) & 339 & 352 & 341 & 343 & 339 & 352 \\
\hline Any recurrent VTE events during follow-up (\%) & 2.5 & 0.9 & 2.9 & 1.9 & 2.5 & 1.8 \\
\hline Average length to recurrent VTE events (days) & 230 & 296 & 252 & 231 & 224 & 256 \\
\hline
\end{tabular}

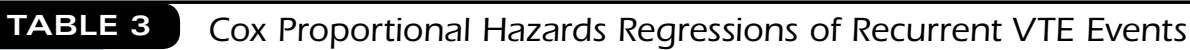

\begin{tabular}{|c|c|c|c|c|c|c|}
\hline & \multicolumn{2}{|c|}{$\begin{array}{l}\text { PDC Analysis } \\
(\mathrm{N}=8,040)\end{array}$} & \multicolumn{2}{|c|}{$\begin{array}{l}\text { MPR Analysis } \\
(\mathrm{N}=7,612)\end{array}$} & \multicolumn{2}{|c|}{$\begin{array}{l}\text { Discontinuation Analysis } \\
\qquad(\mathrm{N}=8,040)\end{array}$} \\
\hline & Hazard Ratio & $\begin{array}{c}\text { 95\% Confidence } \\
\text { Interval }\end{array}$ & Hazard Ratio & $\begin{array}{l}\text { 95\% Confidence } \\
\text { Interval }\end{array}$ & Hazard Ratio & $\begin{array}{c}\text { 95\% Confidence } \\
\text { Interval }\end{array}$ \\
\hline PDC $<0.8$ (noncompliant) & 3.01 & $1.28-4.97$ & & & & \\
\hline MPR < 0.8 (noncompliant) & & & 1.60 & $1.18-2.16$ & & \\
\hline Discontinuation & & & & & 1.48 & $1.09-2.01$ \\
\hline Age: $18-44$ years & Reference & & Reference & & Reference & \\
\hline Age: $45-64$ years & 1.11 & $0.65-1.89$ & 1.10 & $0.65-1.88$ & 1.11 & $0.65-1.88$ \\
\hline Age: $65-74$ years & 1.41 & $0.78-2.57$ & 1.33 & $0.73-2.43$ & 1.39 & $0.76-2.53$ \\
\hline Age: $\geq 75$ years & 1.41 & $0.79-2.52$ & 1.28 & $0.71-2.29$ & 1.37 & $0.76-2.44$ \\
\hline Male & 1.14 & $0.84-1.55$ & 1.10 & $0.80-1.50$ & 1.13 & $0.83-1.53$ \\
\hline Region: West & Reference & & Reference & & Reference & \\
\hline Region: Northeast & 1.14 & $0.62-2.13$ & 1.17 & $0.63-2.20$ & 1.16 & $0.62-2.16$ \\
\hline Region: Midwest & 1.30 & $0.85-1.99$ & 1.35 & $0.87-2.09$ & 1.30 & $0.85-1.99$ \\
\hline Region: South & 1.14 & $0.73-1.78$ & 1.21 & $0.77-1.91$ & 1.14 & $0.73-1.78$ \\
\hline Index event: PE & 0.80 & $0.52-1.24$ & 0.86 & $0.56-1.33$ & 0.81 & $0.52-1.24$ \\
\hline Charlson Comorbidity Index score: 0 & Reference & & Reference & & Reference & \\
\hline Charlson Comorbidity Index score: 1 & 0.92 & $0.52-1.63$ & 0.90 & $0.51-1.60$ & 0.89 & $0.50-1.58$ \\
\hline Charlson Comorbidity Index score: 2 & 1.38 & $0.94-2.02$ & 1.36 & $0.93-2.01$ & 1.38 & $0.94-2.02$ \\
\hline Charlson Comorbidity Index score: $\geq 3$ & 1.13 & $0.75-1.69$ & 1.15 & $0.76-1.73$ & 1.16 & $0.77-1.75$ \\
\hline
\end{tabular}

care models or newly developed anticoagulants that improve compliance and persistence to treatment among these patients.

\section{Limitations}

There are several limitations to this study that are directly related to the administrative nature of the data used. For example, although warfarin dosage might be adjusted frequently (based on INR values), the pharmacy refill records could not capture this information as patients typically do not fill a new prescription each time a dosage adjustment is made. However, we believe the resulting misclassification would lead to an underestimate of the associations observed, and, on this basis, we believe that our findings are conservative. Additionally, pharmacy refill records may not reflect actual consumption, which would ideally be tracked at the patient level using methods such as electronic cap monitoring, as used by Platt et al. in their study of daily adherence to warfarin..$^{18}$ Furthermore, early discontinuation of warfarin treatment may have been for medical reasons, based on risk-benefit assessments for which we have no information. However, we believe that this limitation is conservative, resulting in patients who discontinued for medical reasons being misclassified as noncompliant. Another limitation of this study is that, because of our selection criteria, the generalizability of our findings are limited to those who survived without a VTE event for at least 1 year after the index event. However, when we conducted a sensitivity analysis that included these patients, our results proved to be robust. Additionally, unobservable confounders may exist that could have resulted in biased estimates. Lastly, the patterns observed in this analysis should only be interpreted as associative rather than causative.

\section{Conclusion}

Although long-term warfarin is recommended for patients who have had VTE and are at high risk of recurrence, warfarin utilization was suboptimal for this population. Noncompliance 
TABLE 4 Sensitivity Analysis of Cox Proportional Hazards Regressions Including Patients with VTE Events During 1-Year Warfarin Assessment Period

\begin{tabular}{|c|c|c|c|c|c|c|}
\hline & \multicolumn{2}{|c|}{ PDC Analysis $(\mathrm{N}=8,237)$} & \multicolumn{2}{|c|}{ MPR Analysis $(\mathrm{N}=7,802)$} & \multicolumn{2}{|c|}{$\begin{array}{l}\text { Discontinuation Analysis } \\
(\mathrm{N}=8,237)\end{array}$} \\
\hline & Hazard Ratio & $\begin{array}{c}\text { 95\% Confidence } \\
\text { Interval }\end{array}$ & Hazard Ratio & $\begin{array}{c}\text { 95\% Confidence } \\
\text { Interval }\end{array}$ & Hazard Ratio & $\begin{array}{c}95 \% \text { Confidence } \\
\text { Interval }\end{array}$ \\
\hline PDC $<0.8$ (noncompliant) & 2.58 & $1.62-4.11$ & & & & \\
\hline MPR $<0.8$ (noncompliant) & & & 1.58 & $1.17-2.12$ & & \\
\hline Discontinuation & & & & & 1.43 & $1.06-1.92$ \\
\hline Age: $18-44$ years & Reference & & Reference & & Reference & \\
\hline Age: $45-64$ years & 1.05 & $0.63-1.74$ & 1.04 & $0.63-1.73$ & 1.04 & $0.63-1.73$ \\
\hline Age: $65-74$ years & 1.30 & $0.73-2.31$ & 1.23 & $0.69-2.20$ & 1.28 & $0.72-2.28$ \\
\hline Age: $\geq 75$ years & 1.30 & $0.75-2.28$ & 1.19 & $0.68-2.09$ & 1.27 & $0.72-2.21$ \\
\hline Male & 1.13 & $0.84-1.53$ & 1.09 & $0.80-1.48$ & 1.12 & $0.83-1.51$ \\
\hline Region: West & Reference & & Reference & & Reference & \\
\hline Region: Northeast & 1.03 & $0.56-1.90$ & 1.06 & $0.57-1.96$ & 1.04 & $0.57-1.93$ \\
\hline Region: Midwest & 1.20 & $0.79-1.81$ & 1.24 & $0.81-1.89$ & 1.20 & $0.80-1.82$ \\
\hline Region: South & 1.06 & $0.69-1.63$ & 1.12 & $0.72-1.73$ & 1.06 & $0.69-1.63$ \\
\hline Index event: PE & 0.89 & $0.59-1.35$ & 0.95 & $0.63-1.44$ & 0.89 & $0.59-1.35$ \\
\hline Charlson Comorbidity Index score: 0 & Reference & & Reference & & Reference & \\
\hline Charlson Comorbidity Index score: 1 & 0.86 & $0.49-1.52$ & 0.85 & $0.48-1.51$ & 0.84 & $0.47-1.48$ \\
\hline Charlson Comorbidity Index score: 2 & 1.34 & $0.92-1.96$ & 1.33 & $0.91-1.94$ & 1.34 & $0.92-1.95$ \\
\hline Charlson Comorbidity Index score: $\geq 3$ & 1.07 & $0.72-1.61$ & 1.09 & $0.72-1.63$ & 1.10 & $0.74-1.65$ \\
\hline $\begin{array}{l}\text { VTE events during l-year warfarin } \\
\text { assessment period }\end{array}$ & 1.46 & $0.65-3.30$ & 1.38 & $0.61-3.13$ & 1.52 & $0.67-3.43$ \\
\hline
\end{tabular}

and discontinuation over a l-year period were associated with a higher risk of recurrent VTE events. Improvements in compliance and persistence with anticoagulation therapy may be a potential strategy for reducing the frequency of and costs associated with recurrent VTE events.

\section{Authors}

SHIH-YIN CHEN, PhD, is Research Scientist, Health Economics; NING WU, PhD, is Research Scientist, Economic Analysis and Solutions; and LUKE BOULANGER, MA, MBA, is Senior Research Scientist and Senior Director, Health Economics and Practice Lead for Economic Analysis and Solutions, United BioSource Corporation, Lexington, Massachusetts. MICHAEL GULSETH, PharmD, BCPS, is Program Director for Anticoagulation Services, Sanford USD Medical Center, Sioux Falls, South Dakota. JOYCE LAMORI, MHS, $M B A$, is Associate Director, Translational Science, Health Economics E Outcomes Research; BRAHIM K. BOOKHART, MBA, MPH, is Director, Health Economics \& Outcomes Research; LARRY FIELDS, $M D$, is Senior Director, Clinical Development; and JEFF SCHEIN, DrPH, MPH, is Senior Director, Health Economics \& Outcomes Research, Janssen Scientific Affairs, LLC, Raritan, New Jersey.

AUTHOR CORRESPONDENCE: Shih-Yin Chen, PhD, Research Scientist, Health Economics, United BioSource Corporation, 430 Bedford St., Ste. 300, Lexington, MA 02420. Tel.: 781-960-0302; fax: 781-761-0147; E-mail: Shih-Yin.Chen@unitedbiosource.com.

\section{DISCLOSURES}

This study was sponsored by Janssen Scientific Affairs, LLC. Chen, Wu, and Boulanger are employees of United BioSource Corporation, to whom Janssen Scientific Affairs, LLC, provided consulting fees for conducting this study. Gulseth is on the speakers bureau for Boehringer-Ingelheim and Janssen Pharmaceuticals and is a paid consultant for Janssen Scientific Affairs, LLC (a Johnson \& Johnson [J\&J] company). LaMori, Bookhart, Fields, and Schein are employees of Janssen Scientific Affairs, LLC, and shareholders of J\&J. Study concept and design and data interpretation were contributed by all authors; data collection was the work of Chen, $\mathrm{Wu}$, Boulanger, LaMori, and Bookhart. The manuscript was written and revised by all authors.

\section{REFERENCES}

1. Beckman MG, Hooper WC, Critchley SE, Ortel TL. Venous thromboembolism: a public health concern. Am J Prev Med. 2010;38(4 Suppl): S495-S501.

2. White RH. The epidemiology of venous thromboembolism. Circulation. 2003;107(23 Suppl 1):I4-I8.

3. Spencer FA, Gore JM, Lessard D, Douketis JD, Emery C, Goldberg RJ. Patient outcomes after deep vein thrombosis and pulmonary embolism: the Worcester Venous Thromboembolism Study. Arch Intern Med. 2008;168(4):425-30

4. Cushman M, Tsai AW, White RH, et al. Deep vein thrombosis and pulmonary embolism in two cohorts: the longitudinal investigation of thromboembolism etiology. Am J Med. 2004;117(1):19-25.

5. Hansson PO, Sorbo J, Eriksson H. Recurrent venous thromboembolism after deep vein thrombosis: incidence and risk factors. Arch Intern Med. 2000;160(6):769-74. 
6. Heit JA, Mohr DN, Silverstein MD, Petterson TM, O'Fallon WM, Melton LJ 3rd. Predictors of recurrence after deep vein thrombosis and pulmonary embolism: a population-based cohort study. Arch Intern Med. 2000;160(6):761-68

7. Summaries for patients. Treatment of venous thromboembolism: recommendations from the American College of Physicians and the American Academy of Family Physicians. Ann Intern Med. 2007;146(3):I43.

8. Kearon C, Kahn SR, Agnelli G, et al. Antithrombotic therapy for venous thromboembolic disease: American College of Chest Physicians EvidenceBased Clinical Practice Guidelines (8th ed.). Chest. 2008;133(6 Suppl):454S$545 \mathrm{~S}$

9. Ansell J, Hirsh J, Hylek E, Jacobson A, Crowther M, Palareti G. Pharmacology and management of the vitamin K antagonists: American College of Chest Physicians Evidence-Based Clinical Practice Guidelines (8th ed.). Chest. 2008;133(6 Suppl):160S-198S.

10. Ganz DA, Glynn RJ, Mogun H, Knight EL, Bohn RL, Avorn J. Adherence to guidelines for oral anticoagulation after venous thrombosis and pulmonary embolism. J Gen Intern Med. 2000;15(11):776-81.

11. Deitelzweig SB, Lin J, Kreilick C, Hussein M, Battleman D. Warfarin therapy in patients with venous thromboembolism: patterns of use and predictors of clinical outcomes. Adv Ther. 2010;27(9):623-33.
12. Willey VJ, Bullano MF, Hauch O, et al. Management patterns and outcomes of patients with venous thromboembolism in the usual community practice setting. Clin Ther. 2004;26:1149-59.

13. Andrade SE, Kahler KH, Frech F, Chan KA. Methods for evaluation of medication adherence and persistence using automated databases. Pharmacoepidemiol Drug Saf. 2006;15(8):565-74; discussion: 575-67.

14. Charlson M, Szatrowski TP, Peterson J, Gold J. Validation of a combined comorbidity index. J Clin Epidemiol. 1994;47(11):1245-51.

15. Witt DM, Delate T, Clark NP, et al. Outcomes and predictors of very stable INR control during chronic anticoagulation therapy. Blood. 2009;114(5):952-56.

16. Hylek EM, Chang YC, Skates SJ, et al. Prospective study of the outcomes of ambulatory patients with excessive warfarin anticoagulation. Arch Intern Med. 2000;160(11):1612-17.

17. Caprini JA, Tapson VF, Hyers TM, et al. Treatment of venous thromboembolism: adherence to guidelines and impact of physician knowledge, attitudes, and beliefs. J Vasc Surg. 2005;42(4):726-33.

18. Platt AB, Localio AR, Brensinger CM, et al. Can we predict daily adherence to warfarin? Results from the International Normalized Ratio Adherence and Genetics (IN-RANGE) Study. Chest. 2010;137(4):883-89. 
One-Year Adherence to Warfarin Treatment for Venous Thromboembolism in

High-Risk Patients and Its Association with Long-term Risk of Recurrent Events

\section{APPENDIX Criteria Used to Define High Risk of VTE ${ }^{8}$}

\begin{tabular}{|c|c|c|}
\hline \multicolumn{2}{|c|}{ Stratifying Variables } & Identifying Strategies \\
\hline \multirow{6}{*}{$\begin{array}{l}\text { Reversible } \\
\text { provoking risk } \\
\text { factors during } 3 \\
\text { months prior to } \\
\text { VTE diagnosis }\end{array}$} & $\begin{array}{l}\text { Hormonal contraception or } \\
\text { hormone replacement therapy }\end{array}$ & Prescription of hormonal contraception or hormone replacement therapy \\
\hline & Pregnancy & ICD-9-CM: V22 (normal pregnancy), V23 (high-risk pregnancy) \\
\hline & Fracture & ICD-9-CM: 733.1, 733.93, 733.94, 733.96, 733.97, 733.98, 805-809, 820-829 \\
\hline & Nonfracture trauma & $\begin{array}{l}\text { ICD-9-CM: 836.51-836.52, 836.61-836.64, 836.69, 839.01-839.08, 839.11-839.18, 839.2x- } \\
\text { 839.3x, 839.40-839.42, 839.51-839.52, 839.59, 839.8x, 850.2x-850.4x, 851.x- 853.x, 854.03- } \\
\text { 854.05, 854.1x, 860.x-863.x, 864.02-864.05, 864.1x, 865.01-865.04, 865.09, 865.11-865.14, } \\
\text { 865.19, 866.02-866.03, 866.11-866.13, 867.1x-867.5x, 868.01-868.04, 868.09-868.14, 868.19, } \\
\text { 874.0x, 874.1x, 874.4x-874.5x, 887.x, 896.x-897.x, 900.0x-900.1x, 900.8x-900.9x, 901.x-902.x, } \\
\text { 903.01-903.02, 904.0x, 925.1x-925.2x, 927.0x-927.1x, 927.21, 927.8x-927.9x, 928.0x-928.2x, } \\
\text { 928.8x-928.9x, 950.x }\end{array}$ \\
\hline & Pelvic or orthopedic surgery & ICD-9-CM procedure code: $77.5-77.9,78.5-78.9,79.5-79.9 .80 .5-80.9,81$ \\
\hline & Any hospitalization & Any inpatient stay from the medical claims \\
\hline $\begin{array}{l}\text { Cancer during } 12 \\
\text { months prior to the } \\
\text { index date }\end{array}$ & & $\begin{array}{l}\text { Any hematologic (ICD-9-CM: 200-208), GI (150-159) or respiratory (170-176) cancer; or } 1 \text { inpa- } \\
\text { tient claim with primary diagnosis of cancer (140-208), or } 2 \text { or more outpatient claims within } 3 \\
\text { months of index date, or use of chemotherapy }\end{array}$ \\
\hline
\end{tabular}

